\title{
PACIFIC NORTHWEST LABORATORY \\ MONTHLY REPORT TO THE \\ DIVISION OF ISOTOPES DEVELOPMENT \\ FOR October 1970
}

\author{
Compiled by J. E. Hansen \\ November 15,1970
}

\section{INFORMATION CONCERNING USE OF THIS REPORT}

\section{PATENT STATUS}

This document copy, since it is transmitted in advance of patent clearance, is made available in confidence solely for-use in performance of work under contracts with the U. S. Afomic Energy Commission. This document is not to be pubtistredenits confents otherwise disseminated or used for purposes other than specified above before patent approval for such trelease or use has been secured, upon request, from the Chief, Chieago Patent Group, U. S. Atomic Energy Commission. 9800 So. Cass Ave., Argonne,

\section{PRELIMINARY REPORT}

This repart contains information of a preliminary nature prepared in the course of work under Atomic Energy Commission Contract AT(45-1)-1830. This information is subject to correction or modificat the upon the collection and eveluation of additional data.
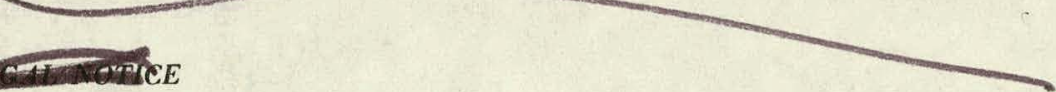

This report was prepared as an account of Government sponsored work. Neither the United States, nor the Commission, nor any person acting on behalf of the Commission:

A. Makes any warranty or representation, expressed or implied, with respecto the acturacy, completeness, or usefulness of the information contained in this report, or that the use of any information, apparatus, method, or process disclosed in this report may nof infringe privately owned rights; or

B. Assumes any liabilities with respeef to the use of or for damages resulting from the use of any information, apparatus, method, or process disclosed in this report.

As used in the above, "person acting on behalf of the Commission includes any employee or contractor of the Commission, or employee of such contractor, to the extent that suchemployee or contractor of the Commission, or employee of such contractor prepares, disseminates, or providesaccess to any information pursuant to his employment or contract with the Commission, or his employment with such contractor.

NOTICE

This report was prepared as an account of work This report was prepared States Government. Neither sponsored by the Unic Energy the United States nor the Unir Stores, nor any of Commission, nor any of their enployes, their contractors, subcontractors, or their makes any warranty, express or implied, or assum legal liability or responsibility for the accuracy, completeness or usefulness of any information, apparatus, product or process disclosed, or represents that its use would not infringe privately owned rights.

PACIFIC NORTHWEST LABORATORY RICHLAND, WASHINGTON

operated by

BATTELLE MEMORIAL INSTITUTE

for the

UNITED STATES ATOMIC ENERGY COMMISSION UNDER CONTRACT AT(45-1)-1830 


\section{DISCLAIMER}

This report was prepared as an account of work sponsored by an agency of the United States Government. Neither the United States Government nor any agency Thereof, nor any of their employees, makes any warranty, express or implied, or assumes any legal liability or responsibility for the accuracy, completeness, or usefulness of any information, apparatus, product, or process disclosed, or represents that its use would not infringe privately owned rights. Reference herein to any specific commercial product, process, or service by trade name, trademark, manufacturer, or otherwise does not necessarily constitute or imply its endorsement, recommendation, or favoring by the United States Government or any agency thereof. The views and opinions of authors expressed herein do not necessarily state or reflect those of the United States Government or any agency thereof. 


\section{DISCLAIMER}

Portions of this document may be illegible in electronic image products. Images are produced from the best available original document. 
THIS PAGE

\section{WAS INTENTIONALLY LEFT BLANK}


DISTRIBUTION - OFFSITE

Division of Isotopes Development, USAEC, Washington, D.C.
W. E. Mott
O. M. Bizzell
J. E. Machurek
R. L. Butenhoff
D. W. Cole
F. D. Haines
R. W. Shivers
J. N. Maddox

Division of Reactor Development \& Technology, USAEC, Washington, D.C. G. W. Cunningham

S. J. Seiken

M. Shaw

Division of Space Nuclear systems, USAEC, washington, D.C.
R. T. Carpenter
G. A. Newby
G. P. Dix
J.A. Powers
M. Klein
F. C. Schwenk

Mound Laboratory, Monsanto Corporation, Miamisburg, Ohio

W. T. Cave

R. I. Neubert

Oak Ridge National Laboratory, Oak Ridge, Tennessee

P. S. Baker

J. H. Gillette

A. F. Rupp

E. E. Beauchamp

Oak Ridge Operations Office, USAEC, Oak Ridge, Tennessee D. C. Davis, Jr.

Richland Operations Office, USAEC, Richland, Washington B. A. Ryan

Sandia Corporation, Albuquerque, New Mexico

A. J. Clark, Jr., Department 9510

G. J. Hildebrandt, Department 9520

Savannah River Laboratory, Aiken, South Carolina D. H. Turno

Savannah River Operations Office, USAEC, Aiken, South Carolina W. D. Sandburg 


\section{DISTRIBUTION - ONSITE (BNW)}

J. L. Bates

R. E. Burns

T. D. Chikalla

F. T. Cross

G. J. Dau

D. R. de Halas

J. L. Deichman

D. E. Deonigi

K. Drumheller

J. W. Finnigan

H. T. Fullam

V. L. Hammond

J. E. Hansen (2)

A. J. Haverfield

J. H. Jarrett

R. W. MoKee

J. E. Minor

L. K. Mudge

D. R. Newman

R. E. Nightingale

R. W. Perkins

I. D. Perrigo

F. P. Roberts

C. A. Rohrmann

K. J. Schneider

W. Vali

H. H. Van Tuyl

J. B. Vetrano

E. J. Wheelwright

N. A. Wogman

Technical Files (3) 


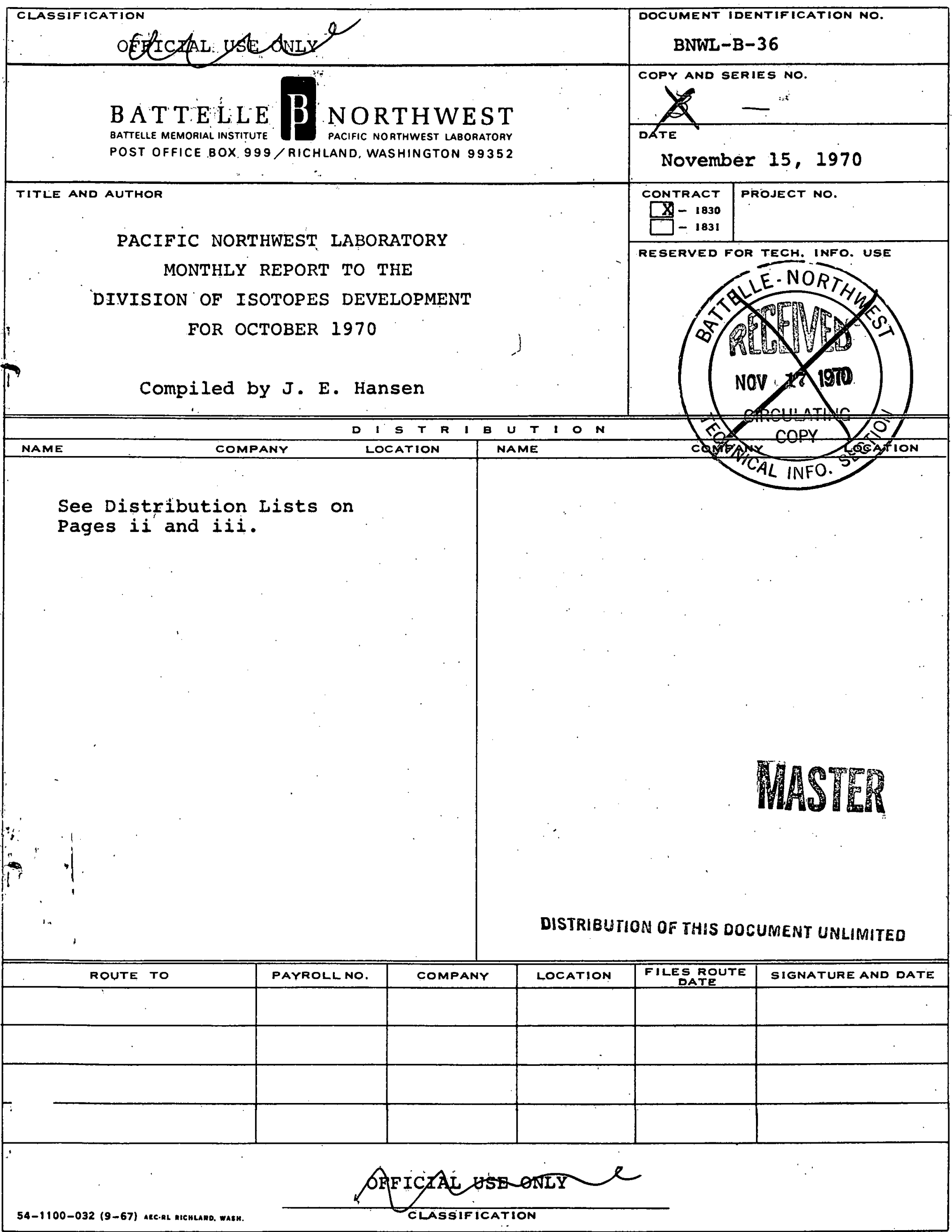


PACIFIC NORTHWEST LABORATORY MONTHLY REPORT TO THE DIVISION OF ISOTOPES DEVELOPMENT FOR OCTOBER 1970

08-01. RADIOISOTOPES PRODUCTION AND MATERIALS DEVELOPMENT

\section{8-01-03. FISSION PRODUCTS}

I. LOW COST CESIUM AND STRONTIUM SOURCES - H. H. Van TuYl, H. C. Stidham, and W. E. Keder

The objective of this program is to provide technology for the production of inexpensive Cs and $S r$ sources by using the purified compounds generated in the Hanford Waste Management Program (HWMP). Large scale use of these radioisotopes will require an assessment of the capabilities of HWMP for producing suitable radiation and heat sources, acceptance of the HWMP product by the customer, licensing of the sources, and market development activities.

The goal in FY-2972 is to develop equipment for fabricating smaller diameter sources in the HWMP facility. The incremental cost of producing smaller sources will be evaluated. Prototype sources will be fabricated with nonradioactive feeds, including loading capsules, welding, and NDT. The sources will be tested to determine mechanical integrity. Potential customers will be contacted to stimulate interest in the HWMP sources.

A preliminary evaluation was made of the incentives for a private party to obtain cesium from HWMP (Hanford Waste Management Program) and encapsulate the material in different container configurations. Amortization of facilities and equipment is expected to be on the order of $\$ 150,000$ per year, and 
operating costs will be about $\$ 300$ per final source container. At 5 megacuries of cesium per year and 15 kilocuries of cesium per container, the added costs will be about 5 cents per curie. Under these conditions, the cost of fabrication would just about equal the value derived from increased utilization of cesium due to reduced self absorption and absorption in the container, if the cesium from HWMP sold for 12.5 cents per curie. At lower cesium prices, the additional cost of fabrication could not be fully recovered, while at higher cesium prices the market for cesium would be reduced due to competition from ${ }^{60} \mathrm{Co}$.

This analysis is quite preliminary, but it does show the need for a more detailed study of the incentives for early involvement of private funding for encapsulation. The incentive will mainly depend on assumed sales since amortization of facilities and equipment is the major part of the cost.

The study of $\mathrm{SrF}_{2}$ properties has revealed that $\mathrm{Sr}, \mathrm{Ba}, \mathrm{Ca}$, and $\mathrm{Mg}$ form solid solutions over a sufficiently wide range to permit evaluation of the properties of mixtures from known data. Such is not the case with $\mathrm{Na}$ and $\mathrm{zr}$. These form low-melting eutectics, so that the properties must be measured over the entire range of interest. Some evidence has been obtained in HWMF studies to 1ndicate a low-melting phase present in small amounts. This could be a compound such as $\mathrm{Na}_{2} \mathrm{SrF}_{4}$ which is not soluble in the major portion of the $\mathrm{SrF}_{2}$. The existence and nature of the low-melting phase is being studied further. 
II. RADIATION CHARACTERISTICS OF FISSION PRODUCT Rh AND PQ F. P. Roberts

A. $102 \mathrm{~m}_{\mathrm{Rh}} \mathrm{Half}$-Life

The problems which developed from moving the counting equipment have been resolved and acquisition of data has resumed.

B. Recovery and Purification of ${ }^{144} \mathrm{Ce}$

(Funded under Related Services)

ORNL requested PNL to provide them with $5 \mathrm{kCi}$ of ${ }^{144} \mathrm{Ce}$ of high radiochemical purity. Laboratory development of a purification process using solvent extraction of $\mathrm{Ce}^{+4}$ has been completed and has been demonstrated to satisfactorily remove impurities in the available cerium crude feed. The actual purification is now underway and methods for converting it to a shippable form are being studied.

III. EVALUATION OF LARGE SCALE USES FOR PURIFIED FISSION PRODUCT XENON - C.A. Rohrmann

Of all the fission products, Xe has the highest fission yield. Although many of the Xe isotopes are radioactive, they all have such short half lives that their activity would be insignificant after allowing time for normal fue $z$ reprocessing.

In the past, the extreme rarity of $X e$ in nature has clearly inhibited its consideration for specific large scale uses even where its properties give it definite and unique advantages. But now, Xe could be made available in supprisingly large quantities. Perhaps the most important and beneficial uses of Xe would be for human surgical anesthesia. Another of the potential uses is a filler gas in incandescent light bulbs with significant increase ith both brightness and efficiency. 
The scope of the PNL program is to: (2)

establish the quality of $x e$ which an be accepted

or generally licensed for oonoumer uses, (2)

determine what industries wou-d be interested in evaluating fission product $x e$ for large scale application, (3) distribute specimens. to participating evaluators, (4) compile evaluation results, and (5) prepare a final report on the results of this total effort.

The purification of the first volume (about 300 liters) of fission product xenon at ORNL has been completed. In an effort to meet a range of 1 to $10 \mu \mathrm{Ci}{ }^{85} \mathrm{Kr}$ activity per liter, STP, of xenon, a product of $2 \mu \mathrm{Ci}$ activity was obtained. In addition the xenon purity was nearly 99\%. The principal impurity was $\mathrm{CO}_{2}$ at 1.08 . More than one pass through the equipment was required to achieve these very satisfactory results. A second volume (about 300 liters) was scheduled for final purification early in the next period.

Preliminary contacts with the Food and Drug Administration were begun:

ISOTOPE PRODUCTION EVALUATIONS - R. W. MCKee, B. M. Cole, and R. G. Rau

This program is designed to evaluate major aspects of isotope production. Until recently, the principal source of isotopes has been the $A E C$ production reactors. Now, however, power reactors are rapidly becoming important sources of isotopes. Power reactors also offer attractive proopects for target irradiations. The future avaizability and cost of these unique isotopes depend on full and efficient utilization of the production potential of power reactors, and the inherent value of these materials can have a significant impact on nuclear power costs. 
The scope of this program includes analysis of fast and thermal reactor fuel cycles within the framework of an expanding nuclear power industry to identify the sources, quantities, timing and cost of production of isotopes of potential importance.

A new task to develop an Isotope Data System was initiated in FY-1972. The objective is a computerized, quick-response system for answering queries on isotope properties, availability, applications, shielding requirements, decay compositions, toxicity, and other factors.

\section{A. Fission Product Profitability studies}

The CAESR computer program (described briefly in the September monthly report - BNWL-B-23) was modified to incorporate "S" type market growth curves. This program was designed to evaluate the profitability of various recovery schemes for power-reactor cesium and strontium fission products. Two types of market growth curves were examined for projections reaching 20,40 , and $60 \mathrm{MCi}$ sales in 1990 with curves fitted to the 1965 to $1970 \mathrm{AEC}$ domestic sales data for ${ }^{137} \mathrm{Cs}$. One curve, the Gompertz curve, projected a steeper growth rate in the early years compared to the other, which can be described as a decaying exponent curve. Equations for the two curves are:

Gompertz :

$$
M=e^{\left(K+A B^{T}\right)}
$$

Decaying Exponent:

$$
M=M_{0} e^{\left[r\left(1-e^{-K T}\right) / K\right]}
$$

where $M=$ market at time $T ; A, B, K$, and $r$ are constants, and $\mathbf{r}=$ growth rate at $\mathrm{T}=0$

Results of the price requirement calculation for conditions as outlined in the september report, which includes a 158 return 
on investment over a 10-yr economic life, are shown in Table 1. These results illustrate the high sensitivity of price to market growth rates and market size. They also show the advantage of sharing the cost of basic facilities between two products. Furthermore, they indicate that even with very optimistic growth rates, markets will probably not be large enough to support private enterprise production of cesium earlier than the late 1970's or 1980 .

Other cases have been run to examine the sensitivity of results to other major variables. These results have shown that the most important factors affecting price requirements are: capital cost, market share, return on investment, and economic life. The factors shown to have lesser importance (wide variations have a small effect on results) are operating costs, cost scaling factors, working capital requirements, and learning curve effects.

\section{B. Isotope Data Compilations}

One cycle of updating the data file for the "Nuclide Tables" has been completed with all of the most recently published data from the "Nuclear Data Sheets" now incorporated in the file. A file of gamma energy data has been received from M.A. Wakat, SRL, and is being used for a comparison check with our file. An examination of the most useful and practical method of handling internal conversion effects is underway.

Development of the isotope data system is proceeding on schedule. 
TABLE I

Calculated ${ }^{137} \mathrm{Cs}$ Price Requirements for Single Purpose and Two-Product Plants

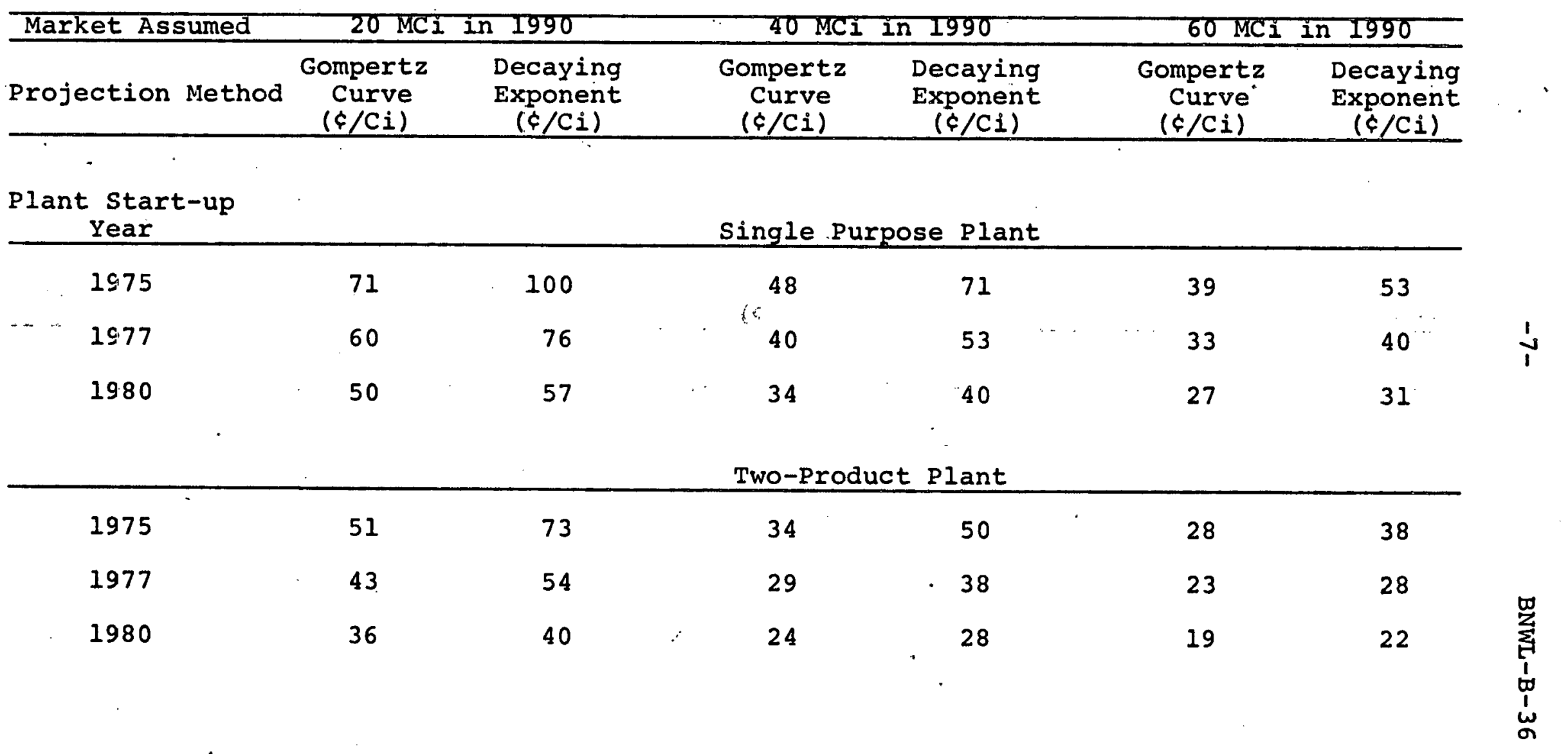


The techniques used in Battelle-Northwest's English Language Information Retrieval system for storing, manipulating, and retrieving large amounts of data was chosen as the best method for handling the physical properties of the nuclides. However, modifications to the existing computer code were necessary to allow for types of data which have no correspondence between nuclides; e.g., the number of known gamma energies for a particular nuclide have no relationship to the number of gamma energies of other nuclides. Efficient storage of this data can be best accomplished by adding a variable length third dimension to the existing two-dimensional matrix storage system.

Other modifications needed to use these data more efficiently are tabling and sorting techniques and a method of processing the data once it is retrieved. Programming the tabling and sorting capabilities has been completed and debugged with the existing two-dimensional system. The basic logic and computer programming for the three-dimensional storage and retrieval capability has been completed and is now being checked and debugged.

08-01-04. SOURCE DEVELOPMENT

I. NONDESTRUCTIVE TESTING OF SOURCES - D. R. Newman

A. NDT Research and Development support

The scope of this program is to develop methods of nondestructive examination of isotopic heat sources developed by DID contractors. Through a number of programs, DID is developing applications for various radioisotopes as heat sources for specific applications. The PNL program will concentrate on the development of methods to assure the long-term mechanical and thermal integrity of the as-manufactured sources. 
Because it is important that NDT methods are compatible with capsule design, le.g. welds should be physically accessible for inspection! the approach of this program is to become involved early with contractors who have design and development responsibilities. Continuing liaison will ensure that NDT methods are available for the source under development.

Work continued on the differential transducer concept and the multielement transducer report. Some additional data on bonding and voids in $\mathrm{SrSiO}_{3}$ aluminum matrix capsules was taken and will be included in the report. A differential transducer is under construction and should be finished during the next month.

An abstract of a paper, "Recent Developments in Nondestructive Testing of Isotope Irradiation and Heat Sources" was submitted for possible presentation at the Third International Symposium on the Packaging and Transportation of Radioactive Materials in Richland, Washington, August 1971.

II. TECHNOLOGY PUBLICATIONS - E. J. Wheelwright

The objective of this program is to provide techiriolugy for the use of $\mathrm{Hm}$ as a radioisotope heat source in aerospace or terrestrial applications. In the past, the program has included development of scientific and engineering data pertinent to: (2) the purification of $P m$ and conversion to a useful fuel form, (2) the design and fabrication of $\mathrm{Pm}$ heat sources and (3) hazards analyses associated with radioisotopic heat sources. Presently, principal emphasis of the program is directed to the dissemination of Pm technology to the technical and scientific community.

The FY- 2972 goal is to complete arrangements for the publication of a book on $\mathrm{Pm}$ technology. 
Twelve chapters of the book on Pm technology were submitted to DID for critique. The remaining four chapters will be submitted for review in November.

On return of the draft from DID, comments will be incorporated and a final internal review will be performed.

III. ADVANCED SOURCE DEVELOPMENT - J. H. Jarrett

A. Advanced Alpha-Photon Source Development

The objective of this program is to evaluate present and future heat and radiatio souroe applioation requiremente and to relate them to present and future encapsulation technology.

The goal of the current work is concerned primarily with the development of thin-film encapsulation and evaluation techniques for alpha/photon sources. Emphasis will be directed toward the technique of sputtering as a means to obtain thin films of radioisotope and containment materials.

Both the glovebox sputtering system and the cold (nonradioisotopic) sputtering system were used in source development work this month. In the glovebox sputtering system beryllium was deposited on glass and polished stainless steel substrates. The substrates were then removed from the glovebox and counted. for alpha activity using a $2 \pi$ gas flow proportional counter. Alpha activity levels detected were quite low; they ranged from $12 \mathrm{dis} / \mathrm{min}$ to $40 \mathrm{dis} / \mathrm{min}$. The results of this experiment are valuable to the source development program for several reasons. Using the techniques developed in this experiment, future radiation sources prepared by sputtering can be removed from the glovebox system without suffering significant contamination, and the final containment layer on the sources may be deposited in essentially a contamination-free condition. The experiment demonstrates 
the feasibility of using a single glovebox sputtering system for the preparation of radiation sources in different sputtering runs with different radioisotopes without significant cross-contamination. Also, the successful deposition of beryllium on ceramic and metallic substrates allows further consideration of beryllium as a candidate encapsulation material for sources that require the substrate and window material to have an atomic number less than 14 .

The cold sputtering system was used to prepare 304 stainless steel deposits on copper and 304 stainless steel substrates under various operating conditions. The coated substrates were then placed in boiling water for extended periods of time to determine their rust resistance. This work was done to explore the results of tests at ORNL which indicated that PNL-prepared sources having a sputtered stainless steel outer layer appeared to be susceptible to rusting when exposed to heated water or heated, high-humidity air. Sixteen specimens of eight different types and four different system conditions were prepared. Eight specimens were placed in boiling water for a number of days, and the remaining eight specimens were held as controls. Table II summarizes the specimen preparation conditions. The same deposition procedure was used for each series of specimens. The air leak rate and the substrate temperature were the only system parameters that were varied significantly, because these were the parameters most likely to have been varied in previous source preparation runs. Table III lists the results of specimen testing. With the exception of specimen 4-SS/Cu significant changes were observed in specimen appearance after exposure to boiling water. In nearly all cases the small areas of apparent rusting were not visible to the naked eye, and no. strong trends dependent on substrate temperature or oxygen. leak rate were observed. The stainless steel layers on all specimens appeared to adhere well. To eliminate the flakes attached to the film surface, 
TABLE II. System Conditions for Depositing 304 Stainless Steel on Copper and Stainless Steel Substrates

\begin{tabular}{|c|c|c|c|c|}
\hline $\begin{array}{l}\text { Specimen } \\
\text { lentification }\end{array}$ & $\begin{array}{l}\text { Substrate } \\
\text { Material }\end{array}$ & $\begin{array}{l}\text { Number } \\
\text { Prepared }\end{array}$ & $\begin{array}{l}\text { Leak Rate* } \\
\text { Torr/Min. }\end{array}$ & $\begin{array}{l}\text { Substrate } \\
\text { Position }\end{array}$ \\
\hline ries 1 & & & & \\
\hline $\begin{array}{l}1-S S / S S \\
1-s S / C u\end{array}$ & $\begin{array}{l}304 \text { SS } \\
\text { copper }\end{array}$ & $\begin{array}{l}2 \\
2\end{array}$ & $\begin{array}{l}3.2 \times 10^{-5} \\
3.2 \times 10^{-5}\end{array}$ & $\begin{array}{l}\text { Direct contact } \\
\text { with base } \\
\text { Direct contact } \\
\text { with base }\end{array}$ \\
\hline
\end{tabular}

Series 2

$\begin{array}{llll}2-S S / S S & 304 \text { SS } & 2 & \begin{array}{l}1.8 \times 10^{-2} \\ \text { at start } \\ 2-S S / C u\end{array} \\ & \text { copper } & 2 & \begin{array}{l}3.5 \times 10^{-3} \\ \text { at end }\end{array}\end{array}$

Direct contact with base Direct contact with base

Series 3

$\begin{array}{llll}3-s s / S S & 304 \text { SS } & 2 & 3.0 \times 10^{-2} \\ 3-S S / C u & \text { copper } & 2 & 3.0 \times 10^{-2}\end{array}$

Series 4

$\begin{array}{llll}4-\mathrm{SS} / \mathrm{SS} & 304 \mathrm{sS} & 2 & 3.0 \times 10^{-2} \\ 4-\mathrm{SS} / \mathrm{Cu} & \text { copper } & 2 & 3.0 \times 10^{-2}\end{array}$

Direct contact with base Direct contact with base

Held $1 / 8$ in. above base with ceramic beads

* The leak rate indicates the change in system pressure per minute measured with the valve to the oil diffusion pump in the closed position. 
TABLE III. The Effect of Boiling Water on ${ }^{304}$ stainless steel Layers Sputter-Deposited Under Various System Conditions

\section{Specimen \\ Identification}

$1-s S / S S$

$1-s s / C u$

2-SS/SS

$2-s s / C u$

$3-s s / 5 s$

$3-s s / C u$

4-SS/SS

4-ss/Cu
14

Days exposed to boiling water

21

21

21

21

14

14

14
Specimen Appearance before test

Medium shiny, grey

Same

Same

Same

Medium shiny, amber grey, film flakes attached to source surface

Same

Same

Same
Specimen Appearance after test (40X magnification)

Dull grey, several small rust colored areas

Dull grey, three small rust colored areas

Same as 1-sS/SS

Dull grey, two small rust colored areas

Dull amber grey, a few rust colored areas near flakes.

Dull amber grey, no. rust colored areas were located

Same as 3-ss/SS

Dull amber grey, one large rust colored area about $1 / 16$ in. $x 3 / 8$ in. 
the air leakage into the system should be less than that giving a closed system pressure change of $3 \times 10^{-2} \mathrm{Torr} / \mathrm{min}$. Since some apparent rusting of the sputtered 304 stainless steel layers was observed, this material will not be used on containment windows for sources to be prepared in the near future. The use of stainless steel alloys having higher concentrations of nickel and chromium will be considered for future radiation sources, since such alloys should not be as susceptible to rusting. Present plans are to investigate the use of sputtered nickel as the containment window material for the next radiation sources that are prepared.

A paper, "Thin Film Radiation Sources using RF Sputtering Techniques," was presented by J. H. Jarrett on October 19, at the 1970 TMS Fall Meeting in Cleveland, Ohio. The meeting was co-sponsored by AIME and ASM.

$$
\text { 08-02. THERMAL APPLICATIONS }
$$

08-02-01. CIRCULATORY SUPPORT SYSTEMS - F. T. CrOsS \& J.C. Sheppard

A. Radiation Characteristics - Nonpromethium Systems

The objective of this program is to determine the dose from radioisotopic heat sources suitable for circulatory support systems. This is accomplished by measuring the dose rates within and surrounding various tissue equivalent phantoms.

Part of the program concerns the prediction of the measured dose rates by the development of computational codes. The computer codes are also used in parametric studies and for the prediction of the in-phantom dose rates from sources not available for measurement. 
Work continues on the measurements of dose rates from implanted ${ }^{252} \mathrm{Cf}$ sources and on the computation of the photon dose rates to various organs in a standard man from a tantalum-encased 30watt $238 \mathrm{pu}$ source implanted in the abdominal cavity. About 100 source kernels were uniformly distributed throughout the plutonium, and dose rates were calculated for dose points that were uniformly distributed throughout the organ of interest. The organ geometries developed by snyder, Ford, and Warner were used for most cases, except for the heart and bladder, where spherical geometries were used. These dose rates are shown in Table IV.

\section{8-03. RADIOISOTOPE SYSTEMS DEVELOPMENT}

08-03-03. OCEANOGRAPHIC AND NATURAL RESOURCE APPLICATIONS

\section{MARINE SYSTEMS}

A. Nuclear Techniques for Seabed Mineral Exploration R. W. Perkins and N. A. Wogman

Recent $P N L$ studies of the composition of deep ocean sediments demonstrated that various mineral deposits and commercial-grade ores can readily bo idontifisd by neutron activation and instrument analysis. From preliminary analysis, it is evident that the elemental composition of most mineral deposits can be easily identified at concentrations we $2 z$ below those of economic importance. Actual experience with $C f-252$ as a neutron source has confirmed these conclusions. Two methods for in-place seabed mineral exploration are being investigated: the first involves placing a neutron source and detector system on the ocean floor; the second method involves bringing samples on board ship and employs a shipboard Cf-252 irradiator and a Ge(Li) spectrometer. The former has the advantage of very rapid analyses, and the latter provides definition of mineral depth profiles from core samples. 
TABLE IV. Gamma Dose Rates to "Mathematical" Organs (a)

\begin{tabular}{|c|c|c|c|}
\hline Organ & $\begin{array}{l}\text { Assumed } \\
\text { Geometry }\end{array}$ & $\begin{array}{l}\text { Center-Center } \\
\text { Distance (cm) }\end{array}$ & $\begin{array}{l}\text { Average Dose }(\mathrm{b}) \\
\text { Rate (mrad/hr) }\end{array}$ \\
\hline \multirow[t]{2}{*}{ I. Ovary } & Ellipsoid & 9.05 & 6.06 \\
\hline & Center point & & 6.09 \\
\hline \multirow[t]{4}{*}{ Uterus } & El1ipsoid & & \\
\hline & Intersected by plane & 15.4 & 1.41 \\
\hline & Cylinder & & 1.60 \\
\hline & Center point & & 1.45 \\
\hline \multirow[t]{2}{*}{ Bladder } & Sphere & 18.8 & 1.21 \\
\hline & Center point & & 1.17 \\
\hline \multirow[t]{3}{*}{ L. Adrenal } & Ellipsoid & & \\
\hline & Intersected by plane & 24.7 & 0.456 \\
\hline & Center point (Approx.) & & 0.392 \\
\hline \multirow[t]{2}{*}{ Heart } & Sphere & 36.7 & 0.292 \\
\hline & Center point & & 0.287 \\
\hline
\end{tabular}

(a) From $30-\mathrm{W}{ }^{238} \mathrm{Pu}$ source shielded with $0.0765 \mathrm{~cm} \mathrm{Ta}$ 。

(b) $\mathrm{H}_{2} \mathrm{O}$ buildup assumed. 


\begin{abstract}
The ${ }^{252}$ Cf irradiation facility, which consists of a 1.8 mg ${ }^{252} \mathrm{Cf}$ source surrounded with a 12" diameter by 12 " thick paraffin moderator, is being used for irradiation of the various types of mineral and element combinations which would be expected in the floor of seawater or freshwater basins. For these irradiations, 200 pound mineral samples which are simulated by adding known amounts. of the elements of interest to dunite, are placed in a carefully controlled geometry directly below the paraffin moderated ${ }^{252} \mathrm{Cf}$ source. Flux characterization within the irradiated sample has shown that when the sample is saturated with seawater rather than freshwater, the thermal neutron flux is only attenuated by about 308 . The combination of the paraffin moderator together with neutron moderation in the water-saturated mineral samples, results in a highly thermalized flux with thermal to fast neutron ratios in excess of 30 . Both the geometry for the ${ }^{252} \mathrm{Cf}$ irradiation source and the geometry of the Ge(Li) diode for counting, simulate the geometries of the irradiator and detector systems which will be employed in the actual nuclear probe device. Thus, the calibrations will be applicable to the nuclear probe which is presently being designed.
\end{abstract}


Received from ARHCO

Transfers and Shipments

Concentrated Feed

Product

Run 22, $445 \mathrm{Ci} / \mathrm{gm} 8 / 31 / 70$

Run $40,511 \mathrm{Ci} / \mathrm{gm} 8 / 31 / 70$

Run 55, $660 \mathrm{Ci} / \mathrm{gm} \mathrm{8/31/70}$

Run $57,792 \mathrm{Ci} / \mathrm{gm} 8 / 31 / 70$

Waste

Unaccounted

Decay

Total

Production and Transfers

Production

Shipments
136,520

50,020
$16,361,900 \mathrm{Ci}$

$1,498,520$

$5,149,700$

18,995

34,705

78,115

86,500

648,045

$1,304,700$

$7,542,620$

$16,361,900$ 


\begin{tabular}{|c|c|c|c|}
\hline . & Cost & $\begin{array}{c}\text { Cost to } \\
\text { Date } \\
\end{array}$ & Budget \\
\hline 08-01 $\frac{\text { Radioisotope Production and }}{\text { Materials Development }}$ & & - & \\
\hline 08-01-03 Fission Products & & & \\
\hline I. Low-Cost Cs/Sr Sources & 7.1 & 20.5 & 50 \\
\hline $\begin{array}{l}\text { II. Rhodium, Palladium, Ruthenium, } \\
\text { and Technetium }\end{array}$ & 3.2 & 10.2 & 40 \\
\hline III. Xenon & 0.6 & 1.0 & 20 \\
\hline $\begin{array}{c}\text { IV. Evaluation of Isotopes Production } \\
\text { Subtotal } 08-01-03\end{array}$ & $\frac{19.1}{30.0}$ & $\frac{46.8}{78.5}$ & $\frac{90}{200}$ \\
\hline 08-01-04 Source Development & & & \\
\hline I. NDT R\&D Support & 2.3 & 8.5 & 25 \\
\hline Technology Publications & 6.6 & 16.0 & 20 \\
\hline III. Advanced Source Development & $\underline{11.5}$ & 32.9 & 50 \\
\hline Subtotal 08-01-04 & 20.4 & 57.4 & 95 \\
\hline Subtotal 08-01 & 50.4 & 135.9 & 295 \\
\hline
\end{tabular}

08-02 Thermal Applications Development

08-02-01 Circulatory support systems

I. Circulatory support

Subtotal 08-02

$\frac{9.3}{9.3} \quad \frac{32.5}{32.5} \quad \frac{85}{85}$




\begin{tabular}{|c|c|c|c|}
\hline OFFICIAL USE ONLY & & BNI & $3-36$ \\
\hline & Cost & $\begin{array}{c}\text { Cost to } \\
\text { Date }\end{array}$ & Budget \\
\hline 08-03 Radioisotope Systems Development & & & \\
\hline 08-03-03 Oceanographic and Natural & & & \\
\hline Resource Applications & & & \\
\hline I. Marine systems & $(4.4)$ & $\underline{12.6}$ & 60 \\
\hline Subtotal $08-03$ & $(4.4)$ & 12.6 & 60 \\
\hline Total 08 Operating Budget & 55.3 & 181.0 & 440 \\
\hline 08 Equipment Budget & 2.8 & 3.6 & 17.0 \\
\hline Subtotal 08 & $\underline{58.1}$ & $\underline{184.6}$ & $\underline{457}$ \\
\hline Pm Inventory Account & 19.3 & 32.1 & 210 \\
\hline PROGRAM GRAND TOTAL & 77.4 & 216.7 & 667 \\
\hline
\end{tabular}

